\title{
Thermal Characterization and Pyrolysis of Waste Leather Treated with $\mathrm{CoCl}_{2}$ And $\mathrm{MnCl}_{2}$
}

by

\author{
E. Bañón, ${ }^{* 1}$ A. Torró, ${ }^{1}$ A.N. García, ${ }^{2}$ M. León ${ }^{2}$ and A. Marcilla ${ }^{2}$ \\ ${ }^{1}$ Technological Institute for Footwear and Related Industries (INESCOP), \\ Polígono Industrial Campo Alto, P.O. Box 253 E-03600 Elda, Spain. \\ ${ }^{2}$ Department of Chemical Engineering, University of Alicante, P.O. Box 99, E-03080 Alicante, Spain.
}

\begin{abstract}
Leather tanned with different agents was pyrolyzed in the presence of $\mathrm{CoCl}_{2}$ and $\mathrm{MnCl}_{2}$ catalysts. A bovine leather sample tanned with two inorganic tanning agents (chromium and titanium salts) and two organic tanning agents (glutaraldehyde and methylacrylic resin) has been used in this study. The samples were soaked in solutions of $\mathrm{CoCl}_{2}$ or $\mathrm{MnCl}_{2}$ of known concentration. The influence on decomposition temperature and the resultant pyrolysis compounds has been evaluated by using thermogravimetric analysis (TG/DTG) and flash pyrolysis (Py-GC/MS). A multivariate analysis has been applied to the pyrolysis products obtained confirming the effect of the catalyst treatment on leather, specifically on samples tanned with organic agents. According to the results, $\mathrm{CoCl}_{2}$ (higher Lewis acidity) shows a greater influence than the $\mathrm{MnCl}_{2}$ (lower Lewis acidity). The results indicate that the presence of chlorides affects the nature of the pyrolysis products, increasing the yield of the aromatic compounds in all the samples, thus improving the added-value of the volatiles. These catalysts reduced slightly the decomposition temperature.
\end{abstract}

\section{Introduction}

Nowadays waste valorization is of great interest due to the environmental problems derived from waste disposal. Many landfills around the world are reaching their maximum waste level because of the large volume of disposed waste. On average, $427 \mathrm{~kg}$ of waste are landfilled in the EU-27 per inhabitant per year. ${ }^{1}$ While there is an obvious need to minimize the generation of wastes; improvement in technologies for valorizing them will play an important role in mitigating the environmental problems in addition to increasing the economic benefit in the case of industrial wastes. Turning industrial waste into a resource is one key to drive the economy towards a more circular model.

One of the industrial wastes that have been proven to be suitable for waste valorization is leather. Tanning processes generate significant volumes of by-products that can be treated and valorized in many cases. ${ }^{2,3}$ One way for the recovery of leather waste is pyrolysis treatment. Pyrolysis of leather wastes has been discussed in the literature, although it has not been studied in depth. Early studies found in this area were made in 1982 by Muralidhara et al. ${ }^{4}$ Later, Caballero et al., ${ }^{5}$ Yilmaz et al., ${ }^{6}$ and Oliveira et al. ${ }^{7}$ studied different aspects of leather pyrolysis such as thermal decomposition kinetics, pyrolysis in fixed bed reactor and production of activated coal, respectively.

Later, our research group carried out the thermal characterization of leather wastes with different tanning agents, ${ }^{8}$ investigated the suitability of using a sodium hydroxide solution as a modifier for a pyrolytic process, ${ }^{9}$ analyzed the composition of the gases and the liquids obtained in flash and slow pyrolysis of chrome tanned leather waste and the estimation of the calorific values of the different pyrolytic fractions,${ }^{10}$ characterized commercially available leathers in order to obtain information about their composition, characteristics and origin ${ }^{11}$ and developed a kinetic model for chrome tanned leather untreated and treated with $\mathrm{NaOH}$ under different conditions. ${ }^{12}$

More recently, two more references have been found, studying the pyrolysis of chromed tanned leather waste. ${ }^{13,14}$

The pyrolysis allows the valorization of wastes from an energy point of view or as source of added value products. Catalytic pyrolysis is a similar process but improves the waste valorization by reducing the temperature of the decomposition process or increasing the yield of any interesting product.

The effect of pyrolysis by catalyst salts on the decomposition of different lignocellulosic biomass waste has been widely studied. It is known that transition metal ion chlorides are highly active in pyrolysis of different materials. Some papers can be found in the literature related to the study of the catalytic effect of different chlorides on pyrolysis of biomass type materials such as almond shell, ${ }^{15,16}$ cellulose, ${ }^{17,18}$ lignite, ${ }^{19}$ wood ${ }^{20,21,22}$ or algae ${ }^{23}$ and polymeric type materials like PVC, ${ }^{24}$ polyethylene, ${ }^{25,26}$ polycarbonate, ${ }^{27}$ PUR foam ${ }^{28}$ or oil-slime. ${ }^{29}$ But there are no papers published about the catalytic effect of metal chlorides on leather pyrolysis.

*Corresponding author E-mail: elenab@inescop.es

Manuscript received July 27, 2020, accepted for publication October 2, 2020. 
Cobalt(II) and manganese (II) chlorides changed the pyrolysis behavior of almond shells. ${ }^{15}$ When the pyrolysis was carried out in a fluidized bed reactor the products obtained also varied in the presence of both catalysts. The results revealed a decrease in the yield of gas phase while the yield of liquid was kept constant. The effect of pre-soaking treatment produced a considerable variation in the composition of the pyrolytic liquid phase, increasing the percentage of furfural and decreasing the percentage of acetic acid. Thermal behavior of almond shell is also modified by $\mathrm{CoCl}_{2} \cdot{ }^{16} \mathrm{Most}$ of the processes take place at lower temperature in the presence of $\mathrm{CoCl}_{2}$ and there is an increase in the evolution of hydrogen, 2-furaldehyde and chloromethane. However, Khelfa et al. ${ }^{17}$ showed that impregnation of $\mathrm{MnCl}_{2}$ had an insignificant impact on lignin pyrolysis.

The catalytic effect of cobalt chloride on lignite pyrolysis has also been studied, together with other metal chlorides. ${ }^{19}$ While the results showed no significant variation in the decomposition temperature of lignite, the effect of chloride on the yield of the liquid fraction is a noteworthy aspect. Specifically, in the case of soaking pre-treatment with $\mathrm{CoCl}_{2}$ the liquid fraction increases $15 \%$ to $38 \%$ when the lignite is impregnated with $15 \%$ of $\mathrm{CoCl}_{2}$. Some of the major components of the liquid phase, such as phenolic compounds, aliphatic, aromatic and carboxylic groups, increased by $150 \%, 83 \%, 100 \%$ and $200 \%$ respectively with the soaking treatment.

Wan et al. ${ }^{20}$ evaluated the effects of different catalysts on product selectivity of microwave-assisted pyrolysis of corn stover and Aspen wood. Cobalt chloride was one of the catalysts studied. They concluded that the catalysts used increased the bio-oil yield, varying also the other fractional yields in different ways, and GC-MS results showed that the use of the catalysts significantly reduces the number of compounds in the bio-oil. Meanwhile, Özbay et al. ${ }^{21}$ studied the catalytic pyrolysis of waste melamine coated chipboard in a fixedbed reactor at different temperatures in the absence and presence of catalysts. Lewis acids (metal chlorides), bases and basic salts were used as catalysts. They found that the oil produced by Lewis acids contained aldehydes while these compounds could not be observed in the other conditions.

In recent studies, Eibner et al. ${ }^{22}$ found that anhydrous sugar yields were strongly influenced by the presence of metal salt catalyst in pyrolysis of eucalyptus wood. Seven metals - Ce, Mn, Fe, Co, Ni, Cu and $\mathrm{Zn}$ - were selected and impregnated using nitrate salts. Cobalt and manganese were found to inhibit levoglucosan formation while they highly favored the LAC (1-hydroxy-(1R)-3,6-dioxabicyclo[3.2.1] octan-2-one) yield.

Moreover, Chalov et al. ${ }^{29}$ demonstrated that the highest conversion of oil-slime into gaseous and liquid products was observed in the presence of iron subgroup metal chlorides, especially $\mathrm{CoCl}_{2}$. They also studied the influence of a cobalt chloride solution of $5 \mathrm{w} \%$ on the thermal stability of oil-slime by TGA. The results show that the use of cobalt chloride increases the degradation rate, which means that the process is faster at the same temperature settings.

The present paper is focused on studying the influence of cobalt chloride and manganese chloride on the pyrolysis of leather tanned with four different tanning agents with the aim of learning how these catalysts can affect the decomposition of this type of wastes. Catalyst $\mathrm{CoCl}_{2}$ has been selected because, according to the literature, it is one of the most effective catalysts on lignocellulosic materials. In the case of $\mathrm{MnCl}_{2}$, it has been selected because of its lower Lewis acidity than that of $\mathrm{CoCl}_{2}$ at a constant chloride counter anion. Differences in the catalysts' acidity level are only due to differences in the cations (size and electronegativity). Thermogravimetric analysis and flash pyrolysis of samples in a pyro-probe device were carried out to determine the catalytic effect of these metal chlorides on leather pyrolysis. Afterwards, multivariate statistical analysis techniques were used for the pyrolytic data treatment, allowing us to perform the comparison and analysis of the results in a more objective way.

\section{Materials and Experimental Equipment}

\section{Materials}

The experiments were carried out on bovine leather tanned with four different tanning agents. Two of them were inorganic tanning agents (chromium (III) and titanium (IV) salts) and the other two were organic tanning agents (glutaraldehyde and methylacrylic polymer). The proximate and ultimate analysis of the original samples can be found elsewhere. ${ }^{8}$

In order to prepare the solutions of the metal chlorides, powdered manganese chloride $\left(\mathrm{MnCl}_{2}\right)$ with purity greater than $99 \%$ and powdered cobalt chloride $\left(\mathrm{CoCl}_{2}\right)$ with purity greater than $98 \%$, both from Sigma-Aldrich, were used. Solutions were prepared just before their use.

\section{Thermobalance}

Thermogravimetric analysis was carried out in a TGA/SDTA 851 Mettler-Toledo thermo-balance in a nitrogen atmosphere with a flow rate of $50 \mathrm{ml} \mathrm{min}^{-1}$. The temperature of the sample was measured with an $\mathrm{R}$ type thermocouple. The temperature values used were those recorded by the probe of the device, located under the crucible, and not the programmed values.

\section{Pyroprobe connected online with a Gas Chromatograph (Py-GC/MS)}

For the flash pyrolysis of the samples, a pyroprobe 5250 device was used. The capillary sample tube was automatically introduced into the center of a platinum resistor, which was heated up in an inert atmosphere. The products generated in pyrolysis were analyzed by using gas chromatograph $(\mathrm{HP}-6890 \mathrm{~N})$ with a capillary column HP5MS, provided with a mass spectrometry detector (HP-5973 MSD). 


\section{Experimental Procedure}

\section{Thermobalance}

The temperature range selected for the study was $25^{\circ}$ to $800^{\circ} \mathrm{C}$ with a nominal heating rate of $10^{\circ} \mathrm{C} \mathrm{min}^{-1}$. The amount of sample analyzed was around 7-8 mg, taken as two cylindrical portions of $2 \mathrm{~mm}$ diameter. The tanned leathers were approximately $2 \mathrm{~mm}$ thick.

All the tests were carried out in duplicate to evaluate the repeatability of the test. It was found to be good as the curves overlapped and the mean absolute difference between duplicates ranged between $0.1 \%$ and $0.9 \%$ of weight loss in TG curves and $0.0001 \% \mathrm{~s}^{-1}-0.001 \% \mathrm{~s}^{-1}$ in DTG curves

At the start of the study, the equipment was calibrated using indium and aluminum standards; later periodic checks were made to ensure that the equipment remained according to the calibration specifications.

\section{Pyroprobe connected online with a Gas Chromatograph (Py-GC/MS)}

The amount of sample pyrolyzed in each experiment was approximately $150 \mu \mathrm{g}$, introduced into a quartz capillary tube. The capillary was automatically introduced into the center of a platinum resistor, which was heated in an inert atmosphere. The parameters used in this process were nominal heating rate, $20^{\circ} \mathrm{C} \mathrm{ms}^{-1}$; pyrolysis time, $20 \mathrm{~s}$; and process temperature of $500^{\circ} \mathrm{C}$.

The resultant pyrolysis products were rapidly removed from the reaction zone (quartz capillary surrounded by the resistor) using a flow of helium, through a transfer line at a temperature of $280^{\circ} \mathrm{C}$ until introduced into the gas chromatograph provided with a
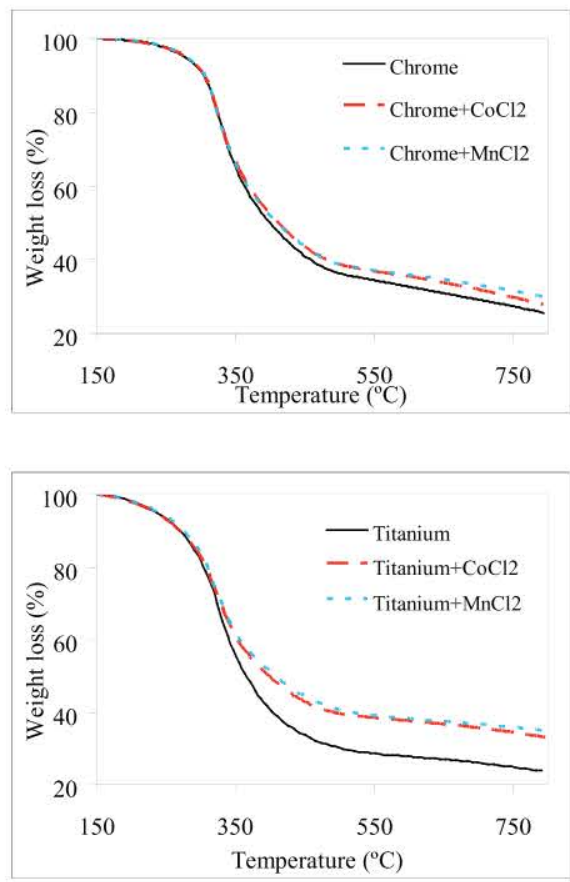

mass spectrometry detector for analysis. The volatile compounds generated were analyzed using an HP-5MS (30-m-long and $0.250 \mathrm{~mm}$ internal diameter) capillary column. The conditions used for the analysis were $\mathrm{T}_{\text {initial }}=37^{\circ} \mathrm{C}, \mathrm{T}_{\text {final }}=320^{\circ} \mathrm{C}$, heating rate $=12^{\circ} \mathrm{C} \mathrm{min}{ }^{-1}$, and $t_{\text {total }}=33.5 \mathrm{~min}$. The qualitative analysis of the chromatogram obtained was carried out using the mass spectra commercial libraries WYLEY275 and NIST02.

\section{Chloride Treatment Process}

For the $\mathrm{CoCl}_{2}$ and $\mathrm{MnCl}_{2}$ soaking process, a circular test-piece of leather, of $34 \mathrm{~mm}$ diameter, was immersed in $10 \mathrm{ml}$ of water-based solution with a known chloride concentration resulting in a ratio of the liquid phase to the solid phase of $8 \mathrm{ml} \mathrm{g}^{-1}$. Concentration of chloride solutions was $5 \%$ and a soaking time of $100 \mathrm{~min}$ were used.

The leather was dried under controlled temperature and relative humidity conditions for $48 \mathrm{~h}$ and stored in a desiccator before use.

\section{Multivariate Analysis}

The IBM SPSS 19.0 for Windows software was used in this study for data analysis and evaluation. The principal component analysis (PCA) was applied to analyze the interrelationships among a large number of variables (in our case the selected compounds). A cluster analysis was also performed which allows the grouping of cases or variable of a data file according to the likeness of similarity between them.

\section{Results and Discussion}

\section{Thermogravimetric Study}

Treated samples were subjected to a thermogravimetric analysis to assess the effect of both chlorides in the decomposition temperature of the samples.
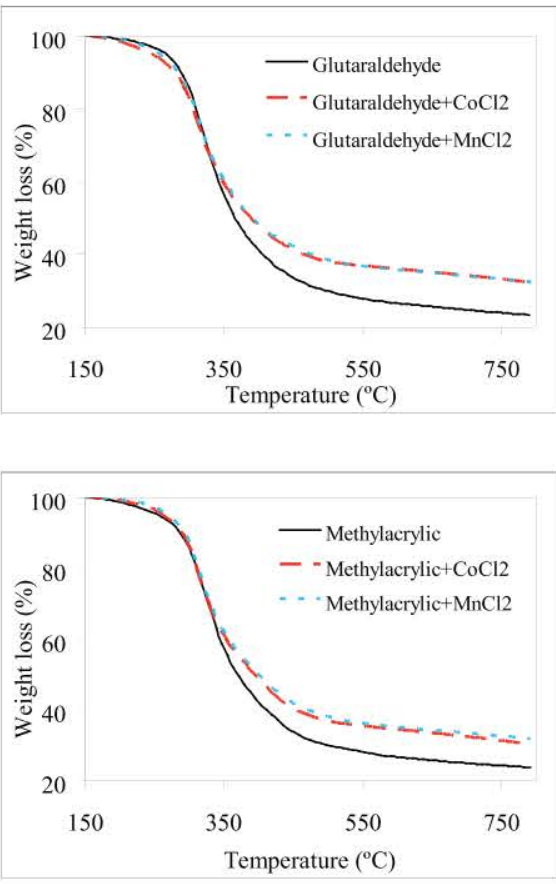

Figure 1. TG curves of treated and untreated samples 

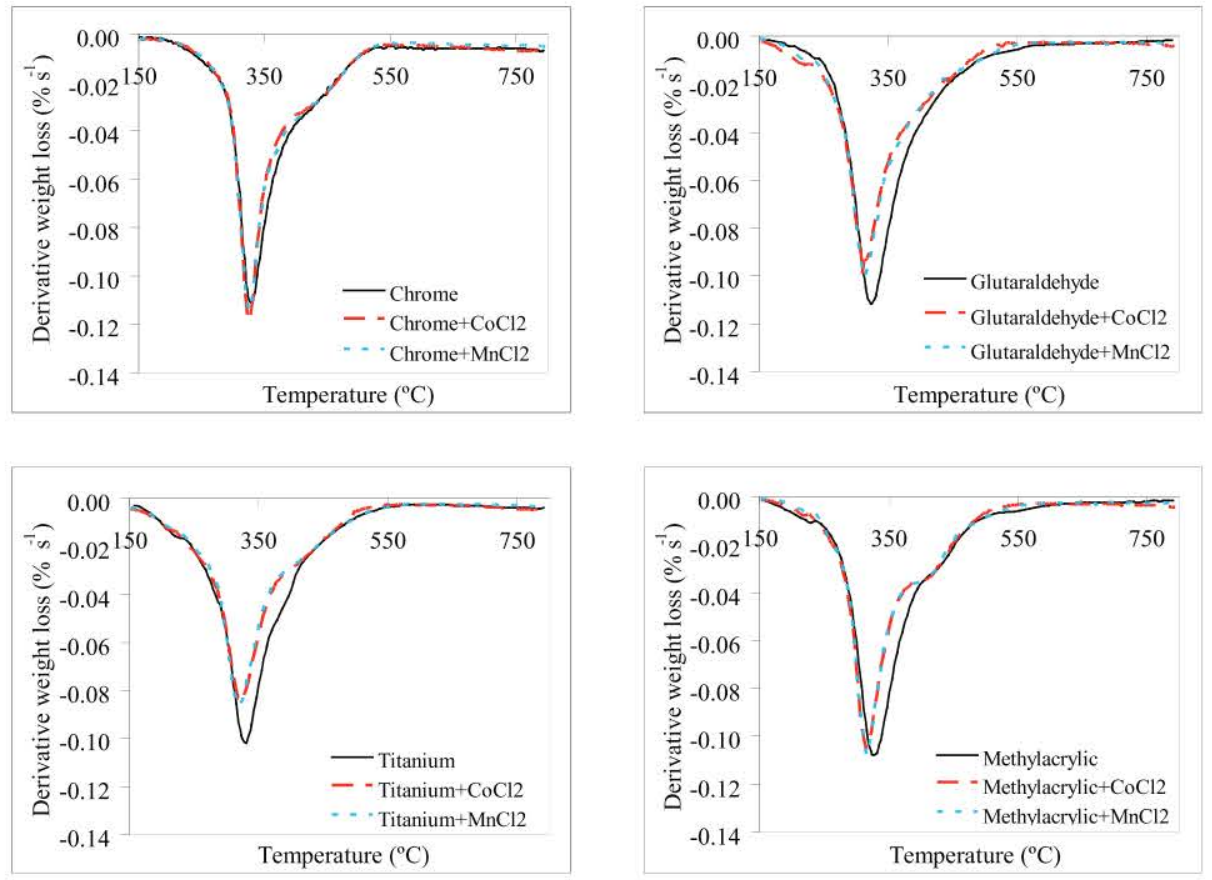

Figure 2. DTG curves of treated and untreated samples

Figures 1 and 2 show the TG and DTG curves, respectively, obtained for each of the four leather samples studied (chrome, glutaraldehyde, titanium and methylacrylic polymer as tanning agents), before and after the chloride soaking treatment process.

In general, graphs show that chloride soaking treatment slightly affects the decomposition pattern of all samples. In TG graphs it can be observed that the treatment influences on the final residue and the main decomposition step of the samples. In all four types of leather, chloride treated samples show greater final residue than original samples. A subsequent determination of the ash content in studied leather samples indicates that the increase in the ash content is similar to the increase of mass percentage due to the respective chloride uptake. Besides, both chlorides show similar variation of the final residue.

The influence on the main decomposition step is more apparent in the DTG graphs where the main peak shifts slightly to lower temperatures with respect to the curves corresponding to untreated samples. Table I shows the temperature for maximum decomposition rate of the samples. This table shows the average value of duplicated tests.

In all samples, the main decomposition temperature decreases, with a difference in temperature that ranges from about $4^{\circ} \mathrm{C}$ in the case of chrome tanned leather to $8^{\circ} \mathrm{C}$ in the case of titanium tanned leather. A decrease in temperature was also reported by Chalov et al. ${ }^{29}$ by working on thermal decomposition of oil-slime, where the use of cobalt chloride decreased the thermal stability of the sample resulting in the decrease of the temperature of the maximum rate of weight loss, from $465^{\circ} \mathrm{C}$ to $440^{\circ} \mathrm{C}$. A decrease in the thermal decomposition temperature implies a higher energy efficiency of the process. In general, for all four types of leathers, behavior of samples treated with manganese chloride is very similar to the samples treated with cobalt chloride since curves overlap. No significant differences can be observed between results obtained with both chlorides.

Table I

Temperatures for maximum decomposition rate of leather tanned with different tanning agents before and after chloride soaking treatment

\begin{tabular}{lccccc} 
Tanning agent & $\begin{array}{c}\mathrm{T}_{\text {original sample }} \\
\left({ }^{\circ} \mathrm{C}\right)\end{array}$ & $\begin{array}{c}\mathrm{T}_{\text {CoC12 sample }} \\
\left({ }^{\circ} \mathrm{C}\right)\end{array}$ & $\begin{array}{c}\Delta \mathrm{T} \\
\left({ }^{\circ} \mathrm{C}\right)\end{array}$ & $\begin{array}{c}\mathrm{T}_{\text {MnC12 sample }} \\
\left({ }^{\circ} \mathrm{C}\right)\end{array}$ & $\begin{array}{c}\Delta \mathrm{T} \\
\left({ }^{\circ} \mathrm{C}\right)\end{array}$ \\
\hline Chrome & 330.7 & 326.5 & -4.2 & 326.6 & -4.1 \\
Glutaraldehyde & 320.5 & 313.6 & -6.8 & 314.1 & -6.3 \\
Titanium & 326.7 & 319.4 & -7.3 & 318.7 & -8.0 \\
Methylacrylic & 323.2 & 316.5 & -6.7 & 315.9 & -7.3
\end{tabular}


The sample less influenced by the treatment is chrome tanned leather where curves with and without chlorides almost overlapped, the final residue is quite similar, and the temperature of the main decomposition peak only shifts about $4^{\circ} \mathrm{C}$. Parallel works of this research group show that chrome is the tanning agent that modifies most the collagen structure, since chromium salts form the more stable bonds with collagen due to their fixation to lateral collagen strands by coordinate covalent bonds, thus, chromium prevents any other agent from varying the thermal decomposition of chrome tanned leather.

Methylacrylic and titanium tanned leathers are the most influenced samples since small shoulder at around $400^{\circ} \mathrm{C}$ appears better defined after the chloride treatments. Previous studies on thermal decomposition of leather ${ }^{11}$ indicated that two parallel reactions can explain the main decomposition peak and the shoulder at around $400^{\circ} \mathrm{C}$. The fact that the shoulder is more visible in chloride treated samples can be explained by a higher effect of chlorides in only one of the processes, in this case the main decomposition step, resulting in a higher separation and better definition of both peaks.

\section{Flash pyrolysis in a Py-GC/MS system}

Flash pyrolysis of samples generated a great distribution of products. Figure 3 shows details of the pyrogram obtained for each of the samples studied. The abundance of each peak has been normalized by the value of the maximum peak. Significant differences in peak distribution have been marked on the graphs.

Since there was a linear relationship between the total area of the pyrogram and the amount of sample pyrolyzed, all peaks detected
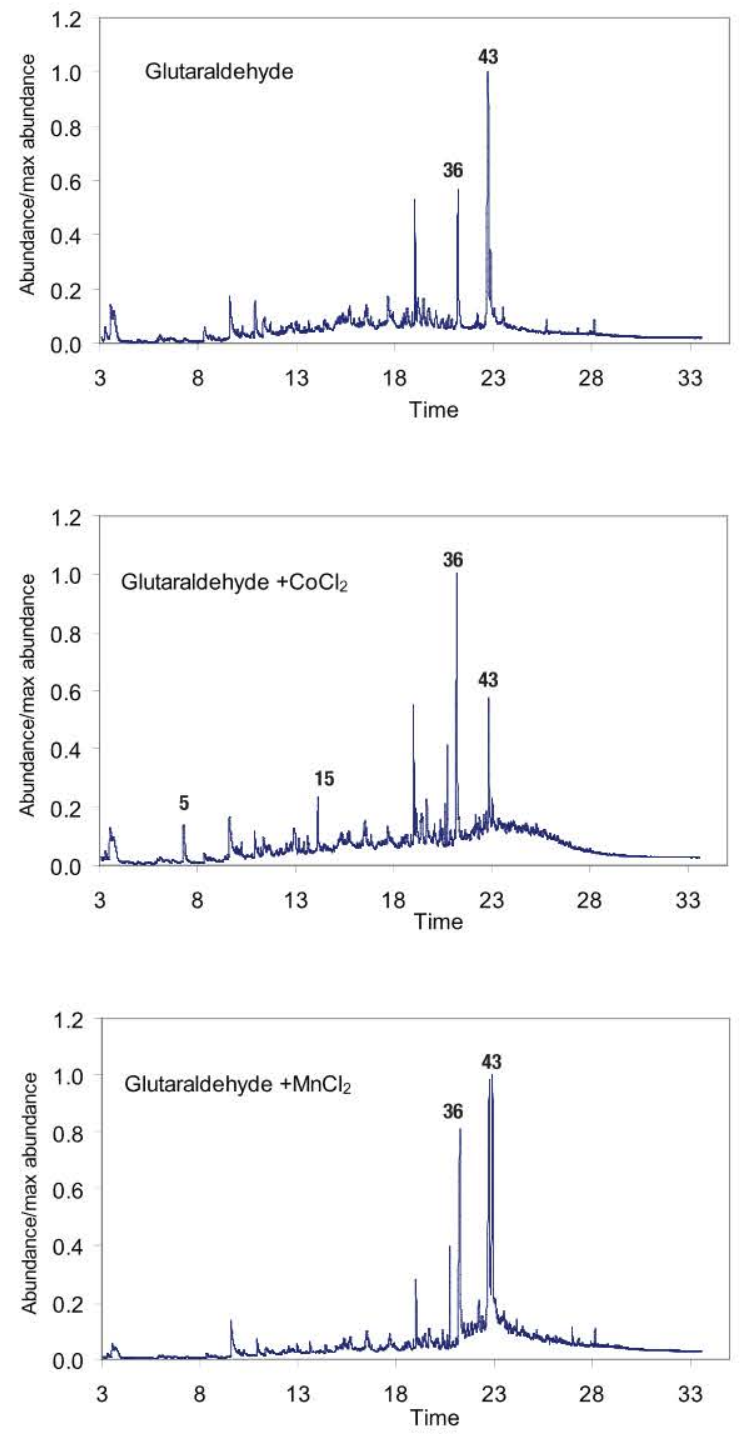

(b)

(a)

Figure 3. GC-MS chromatograms of tanned samples: (a) chrome tanned leather, (b) glutaraldehyde tanned leather. 
were normalized with regard to the total area of the chromatogram. Similar to the data processing carried out in previous studies, ${ }^{8,9}$ all peaks in each pyrogram were integrated. Chromatographic peaks with a relative area higher than $0.5 \%$, in at least one of the samples, were selected and identified. Tests were done by duplicate and the mean area of duplicates was calculated. The addition of all peaks goes from $84 \%$ of the total chromatogram in chrome tanned leather to $60 \%$ in methylacrylic tanned leather treated with $\mathrm{MnCl}_{2}$. Table II shows the list of compounds identified according to this criterion, together with their area percentage in each sample. The values reported correspond to the average value of the experiments in duplicate. The relative error is around $20 \%$, which is a usual value in this type of experiments. The highest values correspond to the smallest peak areas.
Table II shows the presence of a great number of nitrogen containing compounds, similarly to the results reported previously on pyrolysis of untreated samples and samples treated with sodium hydroxide. ${ }^{7}$ The number of these compounds reaches over one third of the detected compounds which is not usual in other biomass. These compounds are derived from the amide/amine groups of leather collagen. The greater area percentage are observed in long chain acids, like hexadecanoic acid (\#40), 9-octadecenoic acid (\#43) and octadecanoic acid (\#44), probably from the fatliquoring step of leather manufacturing. Phenol $(\# 7)$ is observed in a high area percentage in samples with organic tanning agents while it is hardly obtained in samples with inorganic tanning agents, as it was observed in previous studies of different types of tanned leather. ${ }^{8}$ It is also noteworthy the identification of a derivative of cholesterol (cholest-3,5diene \#47) in some of the samples.
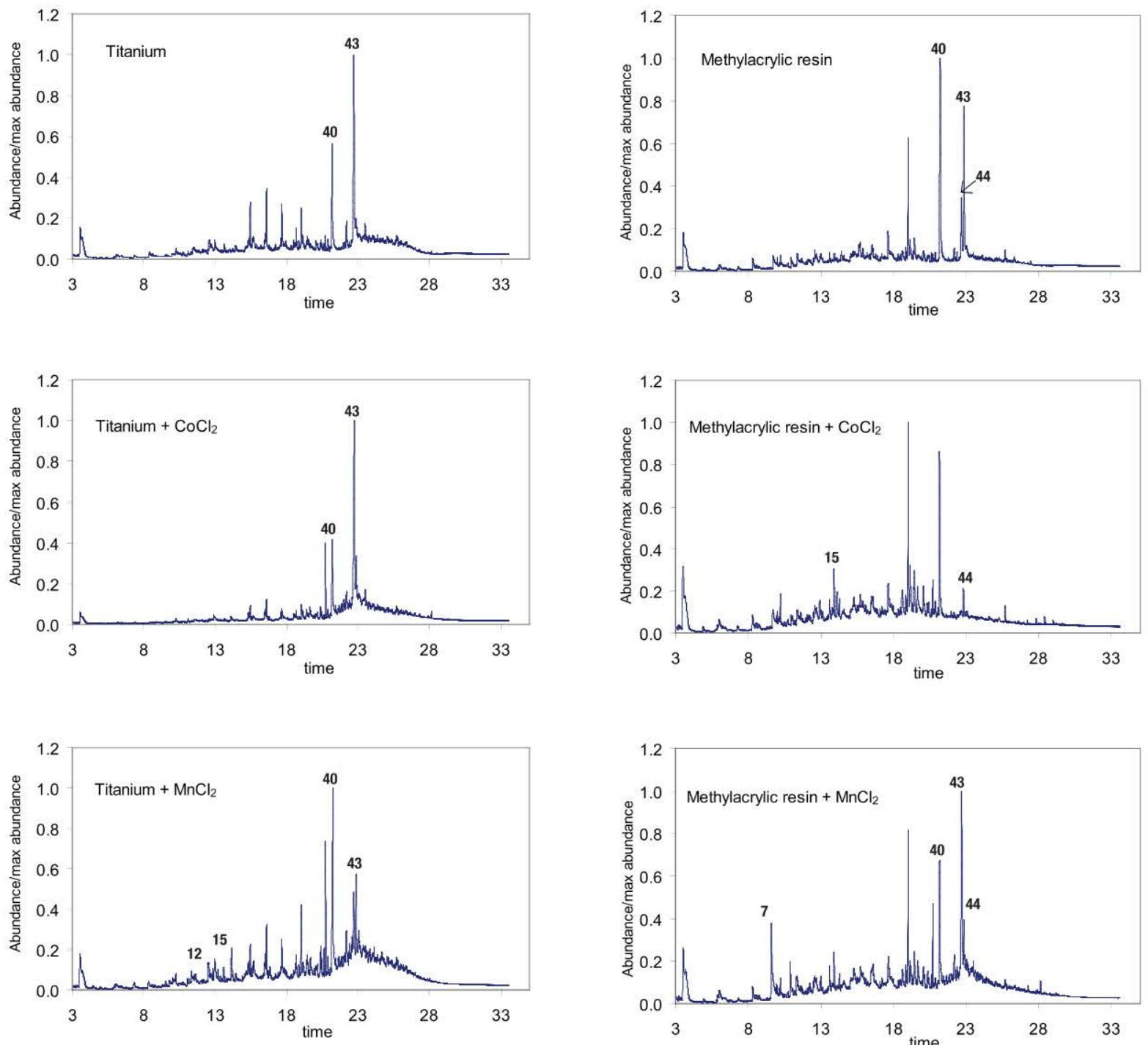

(c)

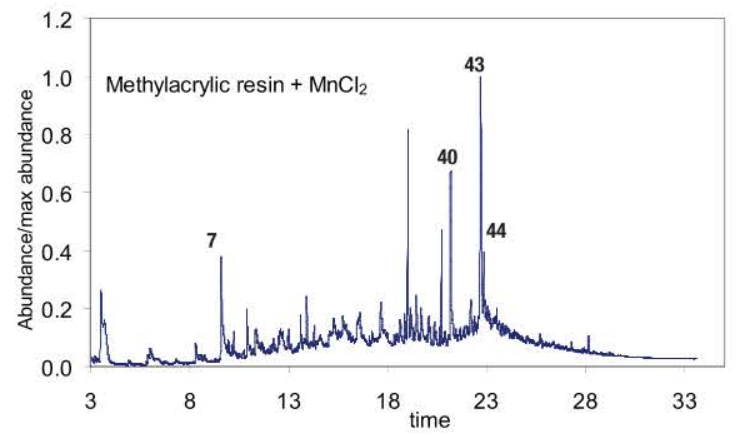

(d)

Figure 3 (continued). GC-MS chromatograms of tanned sample: (c) titanium tanned leather; (d) methylacrylic resin tanned leather.

(12) 2,5-Pyrrolidinedione-3-methyl, (15) nonanoic acid, (40) hexadecanoic acid, (43) 9-octadecenoic, (44) Octadecanoic acid. 


\section{Table II}

Area percentage of identified compounds

\begin{tabular}{|c|c|c|c|c|c|c|c|c|c|}
\hline Peak \# & Group \# & Name & $\begin{array}{c}\text { Match } \\
\text { Quality* }\end{array}$ & $\mathbf{T i}$ & $\mathrm{TiCoCl}_{2}$ & $\mathrm{TiMnCl}_{2}$ & Res & $\mathrm{ResCoCl}_{2}$ & $\mathrm{ResMnCl}_{2}$ \\
\hline 1 & $\mathrm{i}$ & Pyridine & $b$ & 0.134 & 0.119 & 0.783 & 0.195 & 0.236 & 0.185 \\
\hline 2 & $\mathrm{i}$ & 1H-Pyrrole & $\mathrm{b}$ & 3.288 & 2.584 & 4.327 & 4.496 & 6.799 & 5.355 \\
\hline 3 & iii & Toluene & b & 4.187 & 3.520 & 2.649 & 5.933 & 6.880 & 5.394 \\
\hline 4 & $\mathrm{i}$ & 1H-Pyrrole, 3-methyl- & $\mathrm{b}$ & 0.521 & 0.487 & 0.748 & 0.900 & 1.483 & 1.399 \\
\hline 5 & iii & Styrene & $\mathrm{a}$ & 0.280 & 0.299 & 0.581 & 0.574 & 0.486 & 0.275 \\
\hline 6 & $\mathrm{i}$ & 1H-Pyrrole, 2-ethyl- & $\mathrm{b}$ & 0.616 & 0.463 & 0.893 & 1.484 & 1.756 & 1.294 \\
\hline 7 & ii & Phenol & $\mathrm{a}$ & 0.136 & 0.150 & 0.422 & 1.865 & 2.924 & 6.539 \\
\hline 8 & $\mathrm{i}$ & Pyridine, 2,5-dimethyl- & d & $\ldots$ & $\ldots$ & $\ldots$ & 0.469 & 0.993 & 0.545 \\
\hline 9 & ii & Phenol, 2-methyl- & $\mathrm{a}$ & -.- & $\ldots$ & $-\cdots$ & 0.879 & 1.486 & 2.486 \\
\hline 10 & ii & Phenol, 4-methyl- & $\mathrm{a}$ & 1.215 & 0.469 & 0.648 & 1.173 & 0.921 & 1.496 \\
\hline 11 & iv & 1H-Pyrrole-2-carbonitrile & d & 0.327 & 2.380 & 2.326 & 0.979 & 1.278 & 0.861 \\
\hline 12 & vii & $\begin{array}{l}\text { Octanoic acid and 2,5-Pyrrolidinedione-3- } \\
\text { methyl }\end{array}$ & $\mathrm{b}$ & 0.592 & 0.732 & 2.923 & 0.629 & 1.223 & 0.259 \\
\hline 13 & iii & Benzenepropanenitrile & $\mathrm{b}$ & 0.679 & 0.447 & 0.638 & 0.587 & 0.922 & 1.527 \\
\hline 14 & vi & $\begin{array}{l}\text { Cyclopentane, 1,2,3-trimethyl-, } \\
\text { (1.alpha.,2.alpha.,3.beta.)- }\end{array}$ & d & -- & -- & -- & 0.694 & 1.215 & 1.247 \\
\hline 15 & $\mathrm{v}$ & Nonanoic acid & $\mathrm{b}$ & $-\cdots$ & 0.683 & 2.783 & 0.224 & 1.860 & 0.238 \\
\hline 16 & $\mathrm{i}$ & Indole/indolizine & $\mathrm{b}$ & $\ldots$ & $\ldots$ & $\ldots$ & 1.153 & 0.459 & 0.243 \\
\hline 17 & vi & Tetradecene, (E)- & $\mathrm{b}$ & 0.447 & 0.715 & 0.929 & $\ldots$ & -.. & $\ldots$ \\
\hline 18 & $\mathrm{vi}$ & Tetradecane & $\mathrm{a}$ & 1.696 & 0.658 & 0.956 & $\ldots$ & $\ldots$ & $\ldots$ \\
\hline 19 & iv & 4-Pyridinol, 3-amino-2,6-dimethyl- & $\mathrm{d}$ & 0.672 & 0.655 & 0.840 & 1.282 & 0.714 & 0.734 \\
\hline 20 & $\mathrm{vi}$ & Cyclopentane, decyl- & $\mathrm{c}$ & 1.142 & 0.767 & 0.575 & 0.843 & 0.913 & 0.927 \\
\hline 21 & vii & Phthalamide (=1-H-isoindole-1.3(2H)-dione) & $\mathrm{a}$ & -- & -- & -- & --- & -- & -- \\
\hline 22 & vi & Pentadecane & a & 2.414 & 1.155 & 1.618 & $\ldots$ & $\ldots$ & $\ldots$ \\
\hline 23 & vii & $\begin{array}{l}\text { 2-Hydroxy-5-methylcyclohepta-2,4,6-trien-1- } \\
\text { one }\end{array}$ & $\mathrm{b}$ & $\cdots$ & $\cdots$ & -- & 1.630 & 1.956 & 1.239 \\
\hline 24 & $\mathrm{vi}$ & Hexadecane & d & 2.275 & 0.897 & 1.432 & --- & --- & $-\cdots$ \\
\hline 25 & ii & Acetic acid, phenyl ester & d & 0.417 & 0.548 & 0.798 & 0.565 & 1.724 & 1.232 \\
\hline 26 & $\mathrm{vi}$ & Heptadecene & $\mathrm{a}$ & 0.844 & 0.416 & 0.733 & $\ldots$ & $-\ldots$ & $-\cdots$ \\
\hline 27 & $\mathrm{i}$ & 6-Methyl-2,2'-bipyridine 1-oxide & $\mathrm{d}$ & 2.296 & 3.312 & 3.979 & 5.118 & 8.846 & 5.217 \\
\hline 28 & & Unknown 1 & & 0.662 & 1.932 & 0.814 & $\ldots$ & $\ldots$ & $\ldots$ \\
\hline 29 & vii & $\begin{array}{l}1 \mathrm{H}-\text { Pyrrolo[1,2-a][1,4]diazepine-1,5(2H)- } \\
\text { dione, hexahydro }\end{array}$ & d & -- & -- & -- & 1.595 & 3.662 & 1.565 \\
\hline 30 & $\mathrm{v}$ & Tetradecanoic acid & $\mathrm{a}$ & 0.488 & 0.869 & 0.599 & $\ldots$ & $-\ldots$ & $\ldots$ \\
\hline 31 & vii & 3-Phenyl-1H-pyrazole-4-carbaldehyde & d & 0.626 & 0.692 & 1.372 & 1.273 & 2.574 & 1.658 \\
\hline 32 & vii & 1,4-diaza-2,5-dioxobicyclo[4.3.]nonane & $\mathrm{b}$ & 0.533 & 1.839 & 1.459 & 0.366 & 1.593 & 1.283 \\
\hline 33 & vii & 2-Hydroxy-3,5,5-trimethyl-cyclohex-2-enone & d & 0.489 & 0.576 & 0.752 & 0.743 & 1.742 & 1.354 \\
\hline 34 & $\mathrm{vi}$ & 1-Nonadecene & $\mathrm{a}$ & 0.665 & 0.650 & 1.199 & $-\cdots$ & $-\cdots$ & -.- \\
\hline 35 & iv & Pentadecanenitrile & $\mathrm{a}$ & 0.456 & 0.250 & 0.819 & 0.412 & 0.418 & 0.370 \\
\hline 36 & iii & Benzene, (1-methyldodecyl)- & $\mathrm{c}$ & 0.616 & 3.612 & 4.562 & 0.538 & 1.395 & 2.428 \\
\hline 37 & iii & 8,9-Dihydro-7H-cyclopent[a]acenaphthylene & $\mathrm{b}$ & 0.689 & 0.724 & 0.745 & 0.521 & 0.424 & 0.587 \\
\hline 38 & $\mathrm{v}$ & Z-7-Hexadecenoic acid & $\mathrm{a}$ & 0.288 & 0.399 & 0.192 & $\ldots$ & $\ldots$ & $\ldots$ \\
\hline 39 & vii & $\begin{array}{l}\text { 3,9-diazatricyclo[7.3..(3,7)]dodecan-2,8- } \\
\text { dione }\end{array}$ & d & 3.796 & 2.819 & 4.256 & 2.816 & 7.958 & 3.415 \\
\hline 40 & $\mathrm{v}$ & Hexadecanoic acid & $\mathrm{a}$ & 7.186 & 6.577 & 9.932 & 18.248 & $-\cdots$ & 3.415 \\
\hline 41 & vi & 1-octadecene & $\mathrm{b}$ & 0.349 & 0.444 & 0.275 & 0.261 & 0.239 & 0.158 \\
\hline 42 & iv & Oleanitrile & $\mathrm{a}$ & 2.585 & 2.597 & 2.941 & 0.714 & 0.216 & 1.565 \\
\hline 43 & $\mathrm{v}$ & 9-Octadecenoic acid (Z)- & $\mathrm{a}$ & 27.937 & 23.329 & 4.487 & 7.213 & 0.195 & 1.538 \\
\hline 44 & $\mathrm{v}$ & Octadecanoic acid & $\mathrm{a}$ & 2.770 & 2.882 & 3.536 & 1.649 & 1.239 & 1.375 \\
\hline 45 & iv & Hexadecanamide & d & 0.212 & 0.269 & 0.566 & 0.391 & 0.164 & 0.198 \\
\hline 46 & $\mathrm{vi}$ & $\begin{array}{l}\text { Dodecane, 1-cyclopentyl-4-(3- } \\
\text { cyclopentylpropyl)- }\end{array}$ & d & 0.589 & 0.613 & 0.580 & 0.143 & -- & 0.218 \\
\hline 47 & vi & Cholesta-3,5-diene & $\mathrm{a}$ & 0.158 & 0.437 & $-\ldots$ & --- & --- & 0.454 \\
\hline \multicolumn{4}{|c|}{ Total area percentage } & 75 & 73 & 71 & 69 & 67 & 60 \\
\hline
\end{tabular}

* Identification quality: (a) $\geq 95 \%$, (b) $90-94 \%$, (c) $80-89 \%$, (d) $50-79 \%$.

By observing Table II, the significant differences pointed out in pyrograms of Figure 3 among samples untreated and treated with chlorides appear clearly. In all samples, the compounds benzene, (1-methyldodecyl)- (\#36) increased significantly its percentage of area with both chloride treatments. In chrome tanned leather also the yield of hexadecanamide $(\# 45)$ showed a great increase with the treatment the same as cholesta-3,5-diene (\#47) with manganese chloride. In titanium tanned leather it is noticeable the presence of nonanoic acid (\#15) in treated samples, even with an area percentage greater than $2 \%$ in samples treated with manganese chloride, while in the original sample it is not detected, and also the $1 \mathrm{H}$-Pyrrole2 -carbonitrile (\#11) presents a significant increase in the presence of chlorides. Similarly to titanium tanned leather, glutaraldehyde and methylacrylic tanned leather also show a very high increase in 
Table II (continued)

Area percentage of identified compounds

\begin{tabular}{|c|c|c|c|c|c|c|c|c|c|}
\hline Peak \# & Group \# & Name & $\begin{array}{c}\text { Match } \\
\text { Quality* }\end{array}$ & $\mathrm{Cr}$ & $\mathrm{CrCoCl}_{2}$ & $\mathrm{CrMnCl}_{2}$ & Glut & Glut $\mathrm{CoCl}_{2}$ & GlutMnCl $\mathrm{Mn}_{2}$ \\
\hline 1 & $\mathrm{i}$ & Pyridine & $\mathrm{b}$ & 0.176 & 0.136 & 0.162 & 1.876 & 0.632 & 0.359 \\
\hline 2 & $\mathrm{i}$ & 1H-Pyrrole & $\mathrm{b}$ & 2.329 & 2.270 & 2.325 & 3.296 & 2.786 & 1.695 \\
\hline 3 & iii & Toluene & $b$ & 3.838 & 3.415 & 3.219 & 4.644 & 4.669 & 3.435 \\
\hline 4 & $\mathrm{i}$ & 1H-Pyrrole, 3-methyl- & $\mathrm{b}$ & 0.655 & 0.534 & 0.672 & 0.748 & 0.545 & 0.392 \\
\hline 5 & iii & Styrene & $\mathrm{a}$ & 0.377 & 0.549 & 0.736 & 0.357 & 0.714 & 0.338 \\
\hline 6 & $\mathrm{i}$ & 1H-Pyrrole, 2-ethyl- & $\mathrm{b}$ & 0.862 & 0.578 & 0.578 & 1.377 & 0.777 & 0.636 \\
\hline 7 & ii & Phenol & $\mathrm{a}$ & 0.150 & 0.122 & 0.119 & 4.729 & 4.325 & 4.267 \\
\hline 8 & $\mathrm{i}$ & Pyridine, 2,5-dimethyl- & $\mathrm{d}$ & 0.883 & 0.628 & 0.387 & 0.594 & 0.427 & 0.242 \\
\hline 9 & ii & Phenol, 2-methyl- & $\mathrm{a}$ & --- & $-\cdots$ & --- & 2.643 & 2.295 & 1.516 \\
\hline 10 & ii & Phenol, 4-methyl- & $\mathrm{a}$ & 0.643 & 0.232 & 0.311 & 1.870 & 0.443 & 0.717 \\
\hline 11 & iv & 1H-Pyrrole-2-carbonitrile & d & --- & $\ldots$ & $--\cdot$ & 0.245 & 0.375 & 0.347 \\
\hline 12 & vii & $\begin{array}{l}\text { Octanoic acid and 2,5-Pyrrolidinedione-3- } \\
\text { methyl }\end{array}$ & b & 0.942 & 1.363 & 1.364 & 0.326 & 2.413 & 0.343 \\
\hline 13 & iii & Benzenepropanenitrile & $\mathrm{b}$ & 0.431 & 0.475 & 0.677 & 0.428 & 0.680 & 0.773 \\
\hline 14 & vi & $\begin{array}{l}\text { Cyclopentane, 1,2,3-trimethyl-, } \\
\text { (1.alpha.,2.alpha.,3.beta.)- }\end{array}$ & d & $\cdots$ & -- & -- & -- & -- & -- \\
\hline 15 & $\mathrm{~V}$ & Nonanoic acid & $\mathrm{b}$ & $\ldots$ & -.. & -.- & 0.172 & 2.736 & 0.216 \\
\hline 16 & $\mathrm{i}$ & Indole/indolizine & $\mathrm{b}$ & 0.267 & 0.262 & 0.174 & 0.383 & 0.392 & 0.538 \\
\hline 17 & $\mathrm{vi}$ & Tetradecene, (E)- & $\mathrm{b}$ & 0.739 & 1.743 & 1.352 & 0.258 & 0.345 & 0.267 \\
\hline 18 & vi & Tetradecane & $\mathrm{a}$ & 0.245 & 0.358 & 0.357 & 0.118 & 0.124 & 0.112 \\
\hline 19 & iv & 4-Pyridinol, 3-amino-2,6-dimethyl- & $\mathrm{d}$ & 0.790 & 0.539 & 0.898 & 0.961 & 0.698 & 0.834 \\
\hline 20 & vi & Cyclopentane, decyl- & $\mathrm{c}$ & 0.463 & 0.547 & 0.779 & 0.641 & 1.815 & 0.920 \\
\hline 21 & vii & Phthalamide $(=1-\mathrm{H}$-isoindole-1.3(2H)-dione) & $\mathrm{a}$ & 1.355 & 1.148 & 2.174 & 0.836 & 0.512 & 0.348 \\
\hline 22 & vi & Pentadecane & a & 0.836 & 0.726 & 0.635 & 0.589 & 0.154 & 0.293 \\
\hline 23 & vii & $\begin{array}{l}\text { 2-Hydroxy-5-methylcyclohepta-2,4,6-trien-1- } \\
\text { one }\end{array}$ & b & -- & -- & -- & 1.538 & 0.939 & 0.799 \\
\hline 24 & vi & Hexadecane & d & 0.926 & 0.548 & 0.572 & $-\cdots$ & --- & $-\cdots$ \\
\hline 25 & ii & Acetic acid, phenyl ester & d & 0.198 & 0.278 & 0.473 & 0.973 & 0.613 & 0.423 \\
\hline 26 & vi & Heptadecene & a & 0.455 & 0.328 & 0.280 & 0.353 & 0.372 & 0.166 \\
\hline 27 & $\mathrm{i}$ & 6-Methyl-2,2'-bipyridine 1-oxide & $\mathrm{d}$ & 1.987 & 2.148 & 2.282 & 5.949 & 5.460 & 3.715 \\
\hline 28 & & Unknown 1 & & $\ldots$ & $\ldots$ & $\ldots$ & $\ldots$ & $\ldots$ & $\ldots$ \\
\hline 29 & vii & $\begin{array}{l}\text { 1H-Pyrrolo }[1,2-\mathrm{a}][1,4] \text { diazepine- } 1,5(2 \mathrm{H}) \text { - } \\
\text { dione, hexahydro }\end{array}$ & d & 1.534 & 1.187 & 1.213 & 1.715 & 2.722 & 0.753 \\
\hline 30 & $\mathrm{v}$ & Tetradecanoic acid & a & 0.725 & 0.771 & 0.528 & 0.245 & 1.374 & 0.316 \\
\hline 31 & vii & 3-Phenyl-1H-pyrazole-4-carbaldehyde & $\mathrm{d}$ & 1.730 & 1.523 & 1.181 & 1.578 & 1.396 & 1.618 \\
\hline 32 & vii & 1,4-diaza-2,5-dioxobicyclo[4.3.]nonane & $\mathrm{b}$ & 1.124 & 0.622 & 2.667 & 1.622 & 3.412 & 2.682 \\
\hline 33 & vii & 2-Hydroxy-3,5,5-trimethyl-cyclohex-2-enone & d & 0.976 & 0.914 & 0.972 & 1.798 & 0.922 & 0.657 \\
\hline 34 & $\mathrm{vi}$ & 1-Nonadecene & a & 0.163 & 0.284 & 0.252 & 0.488 & 0.394 & 0.284 \\
\hline 35 & iv & Pentadecanenitrile & $\mathrm{a}$ & 0.268 & 0.168 & 0.219 & 0.278 & 1.256 & 0.430 \\
\hline 36 & iii & Benzene, (1-methyldodecyl)- & $\mathrm{c}$ & 0.483 & 2.888 & 2.993 & 0.647 & 2.842 & 2.770 \\
\hline 37 & iii & 8,9-Dihydro-7H-cyclopent[a]acenaphthylene & $\mathrm{b}$ & 0.988 & 0.816 & 0.746 & 0.382 & 0.546 & 0.224 \\
\hline 38 & $\mathrm{v}$ & Z-7-Hexadecenoic acid & $\mathrm{a}$ & 1.388 & 0.473 & 0.218 & 0.129 & 0.258 & 0.339 \\
\hline 39 & vii & $\begin{array}{l}\text { 3,9-diazatricyclo[7.3..(3,7)]dodecan-2,8- } \\
\text { dione }\end{array}$ & d & 6.953 & 1.664 & 5.117 & 4.885 & 8.452 & 7.888 \\
\hline 40 & $\mathrm{v}$ & Hexadecanoic acid & a & 12.293 & 7.192 & 7.874 & 4.885 & 8.452 & 7.888 \\
\hline 41 & vi & 1-octadecene & b & 0.516 & 1.336 & 0.697 & 0.595 & 0.488 & 1.727 \\
\hline 42 & iv & Oleanitrile & a & --- & 0.162 & 0.276 & 0.391 & 0.434 & 0.574 \\
\hline 43 & $\mathrm{v}$ & 9-Octadecenoic acid (Z)- & a & 28.467 & 19.569 & 19.633 & 19.875 & 0.125 & 17.753 \\
\hline 44 & $\mathrm{v}$ & Octadecanoic acid & a & 5.363 & 7.827 & 9.267 & 3.932 & 5.238 & 11.372 \\
\hline 45 & iv & Hexadecanamide & $\mathrm{d}$ & 0.585 & 1.567 & 1.666 & 0.567 & 0.777 & 0.647 \\
\hline 46 & vi & $\begin{array}{l}\text { Dodecane, 1-cyclopentyl-4-(3- } \\
\text { cyclopentylpropyl)- }\end{array}$ & $\mathrm{d}$ & 0.525 & 0.833 & 0.844 & 0.358 & -- & 0.179 \\
\hline 47 & vi & Cholesta-3,5-diene & $\mathrm{a}$ & 0.237 & 0.646 & 1.259 & 0.485 & $--\cdot$ & 0.598 \\
\hline \multicolumn{4}{|c|}{ Total area percentage } & 84 & 69 & 78 & 81 & 74 & 82 \\
\hline
\end{tabular}

* Identification quality: (a) $\geq 95 \%$, (b) $90-94 \%$, (c) $80-89 \%$, (d) $50-79 \%$.

the percentage of nonanoic acid in the presence of cobalt chloride, going from 0.17 in the original glutaraldehyde sample and 0.22 in the original methylacrylic sample to 2.7 and 1.86 in the respective treated sample. In both samples is also noteworthy the decrease of 9-octadecenoic acid (\#43), going from 19.88 in the original glutaraldehyde leather and 7.21 in the methylacrylic leather to 0.13 and 1.20 in the respective samples treated with $\mathrm{CoCl}_{2}$. Another significant decrease is also observed in methylacrylic tanned leather in the case of hexadecanoic acid (\#40), which is not detectable in the sample treated with $\mathrm{CoCl}_{2}$.

For an easier analysis of results, the compounds were grouped according to their principal functional group. Table III shows the percentage of identified compounds classified according to their main 
Table III

Classification and area percentage of identified compounds

\begin{tabular}{|c|c|c|c|c|c|c|c|}
\hline Group \# & Group name & $\mathrm{Ti}$ & $\mathrm{TiCoCl}_{2}$ & $\mathrm{TiMnCl}_{2}$ & Res & $\mathrm{ResCoCl}_{2}$ & $\mathrm{ResMnCl}_{2}$ \\
\hline \multirow{2}{*}{$\mathrm{i}$} & Heterocyclic Aromatic & & & & & & \\
\hline & Compounds (HAC) & 6.855 & 6.965 & 10.729 & 13.816 & 20.571 & 14.239 \\
\hline ii & Phenols & 1.769 & 1.166 & 1.868 & 4.482 & 7.055 & 11.753 \\
\hline iii & Aromatics & 6.451 & 8.601 & 9.176 & 8.154 & 10.107 & 10.210 \\
\hline iv & Nitriles, amines and amides & 4.252 & 6.150 & 7.492 & 3.779 & 2.790 & 3.729 \\
\hline $\mathrm{v}$ & Acids & 38.668 & 34.739 & 21.528 & 27.333 & 3.293 & 6.566 \\
\hline vi & Alkanes and alkenes & 10.578 & 6.752 & 8.296 & 1.942 & 2.368 & 3.005 \\
\hline vii & Ketones and aldehydes & 6.036 & 6.658 & 10.763 & 9.052 & 20.707 & 10.774 \\
\hline Group \# & Group name & $\mathrm{Cr}$ & $\mathrm{CrCoCl}_{2}$ & $\mathrm{CrMnCl}_{2}$ & Glut & GlutCoCl$_{2}$ & GlutMnCl${ }_{2}$ \\
\hline & Heterocyclic Aromatic & & & & & & \\
\hline 1 & Compounds (HAC) & 7.160 & 6.555 & 6.580 & 14.223 & 11.019 & 7.576 \\
\hline ii & Phenols & 0.991 & 0.633 & 0.903 & 10.215 & 7.676 & 6.924 \\
\hline iii & Aromatics & 6.117 & 8.144 & 8.371 & 6.457 & 9.450 & 7.540 \\
\hline iv & Nitriles, amines and amides & 1.644 & 2.436 & 3.060 & 2.443 & 3.538 & 2.831 \\
\hline $\mathrm{v}$ & Acids & 48.236 & 35.832 & 37.520 & 29.239 & 18.183 & 37.883 \\
\hline vi & Alkanes and alkenes & 5.104 & 7.349 & 7.027 & 3.886 & 3.693 & 4.546 \\
\hline vii & Ketones and aldehydes & 14.613 & 8.419 & 14.688 & 14.297 & 20.767 & 15.088 \\
\hline
\end{tabular}

functional group. Seven groups were established: (i) heterocyclic aromatic compounds, which includes pyrrole and pyridine; (ii) phenols, which refers to phenol derivatives; (iii) aromatics; (iv) nitriles, amides and amines, including nitrile derivatives; (v) acids; (vi) aliphatics, including alkanes and alkenes; and (vii) ketones and aldehydes.

In Table III it can be observed that the main group in the original samples is the acids, which area percentage decreases with the chloride treatment in almost all the leather samples, only the glutaraldehyde leather treated with $\mathrm{MnCl}_{2}$ experiments exhibit an increase. This decrease is more pronounced in the methylacrylic sample reaching a decrease of around $35 \%$ of the value in the original sample. This reduction is mainly due to the significant decrease in the amount of 9-octadecenoic acid (\#43) commented on previously, although other acids, like nonanoic acid (\#15), experiment an increase with the treatment. On the other hand, chloride treatment increases the aromatics area percentage in all leather samples, mainly due to the significant increase in the yield of benzene (1-methyldodecyl)(\#36) and the slight decrease of other aromatics like toluene. The group formed by heterocyclic aromatic compounds decreases its yield in chrome and glutaraldehyde tanned samples, while the area percentage increases in titanium and methylacrylic samples. The area percentage of phenolic derivatives decreases in the chrome, glutaraldehyde and titanium samples while increases significantly in methylacrylic sample, mainly due to the increase of phenol (\#7) in this sample. The group formed by ketones and aldehydes decreases slightly with the $\mathrm{CoCl}_{2}$ treatment in the chrome sample while it experiences an increase in the other samples, the same as the $\mathrm{MnCl}_{2}$ treatment. These results in the group of aldehydes are consistent with the ones reported by Özbay et al. ${ }^{20}$ who concluded that Lewis acids favored the formation of aldehydes.

In order to perform a deeper comparative study among the twelve samples (four original samples and the same ones after the $\mathrm{CoCl}_{2}$ and $\mathrm{MnCl}_{2}$ treatments), a multivariate statistical analysis was developed. In this way, the Principal Component Analysis (PCA) and the hierarchical cluster was carried out in such a way that the chromatograms were transformed into a matrix with 24 rows (i.e. including the two replicates of each one of the twelve samples

Table IV

Principal component analysis (PCA). Total variance explained.

\begin{tabular}{|c|c|c|c|c|c|c|c|c|c|}
\hline \multirow[b]{2}{*}{ Component } & \multicolumn{3}{|c|}{ Initial eigenvalues ${ }^{a}$} & \multicolumn{3}{|c|}{ Sum of square loadings extraction } & \multicolumn{3}{|c|}{ Sum of square loadings rotation } \\
\hline & Total & $\begin{array}{c}\% \\
\text { variance } \\
\end{array}$ & $\begin{array}{c}\% \\
\text { cumulative }\end{array}$ & Total & \begin{tabular}{c|}
$\%$ \\
variance \\
\end{tabular} & $\begin{array}{c}\% \\
\text { cumulative } \\
\end{array}$ & Total & $\begin{array}{c}\% \\
\text { variance } \\
\end{array}$ & $\begin{array}{c}\% \\
\text { cumulative }\end{array}$ \\
\hline 1 & 107.036 & 65.106 & 65.106 & 107.036 & 65.106 & 65.106 & 24.343 & 14.807 & 14.807 \\
\hline 2 & 28.354 & 17.247 & 82.353 & 28.354 & 17.247 & 82.353 & 49.670 & 30.212 & 45.020 \\
\hline 3 & 10.765 & 6.548 & 88.901 & 10.765 & 6.548 & 88.901 & 56.521 & 34.380 & 79.399 \\
\hline 4 & 7.429 & 4.519 & 93.420 & 7.429 & 4.519 & 93.420 & 23.051 & 14.021 & 93.420 \\
\hline
\end{tabular}

${ }^{\mathrm{a}}$ Extraction method: Principal component analysis 
studied) and 47 columns (significant compounds identified with a relative area higher than $0.5 \%$, in at least one of the samples). The PCA gave 4 principal components that could account for the $93.4 \%$ of the variance which can be interpreted as an acceptable percentage. Table IV shows, in individual and cumulative percentages, the total proportion of explained variance for each factor, for both rotated (Varimax rotation) and non-rotated solutions. Figure 4 represents the dendrogram obtained from the analysis of the hierarchical clusters, which shows the results of a complete comparison among the samples studied.

The dendrogram in Fig. 4 shows that the experiments are reproducible (first cluster on the dendrogram). In general, organic tanning shows better reproducibility than inorganic tanning. The last cluster is formed by the addition of two main groups, the first upper half of the diagram is comprised by all samples with organic tanning (glutaraldehyde and methylacrylic) original and chloride treated samples, and the lower half is comprised by the samples with inorganic tanning ( $\mathrm{Ti}, \mathrm{Cr}$ ), original and chloride treated. This classification is consistent with the results reported by Marcilla et al. ${ }^{8}$ where in a third level of the hierarchical cluster, mineral tannings were grouped as well as the organic tannings. This observation can indicate that the treatment is not so strong to mask the inherent characteristics of leather due to type of tanning, contrary to what happened with an alkaline treatment with $\mathrm{NaOH}$ reported by Marcilla et al. ${ }^{9}$ where the alkaline treatment made the pyrolysis products of all treated samples more similar between them than those of the corresponding untreated samples.

Within the group of the inorganic tanning, certain symmetry is observed in the behavior of both chrome and titanium tanned samples. In these leathers, chloride treated samples are grouped first in a second level, and then they are grouped with their respective sample without any treatment in a third level. This observation indicates that chlorides have some influence on leather and it is similar for both cobalt and manganese chloride. The last level of this group is formed by the addition of all chrome tanned samples with all titanium tanned samples. Relating these results with those observed in Table II, it can be seen that chloride treated samples have similar area percentage of identified compounds for both chlorides, but they differ from the original leather in benzene, (1-methyldodecyl)(\#36), 7-hexadecenoic acid (\#38), 9-octadecenoic acid (\#43) and hexadecanamide (\#45) for chrome tanned samples, and nonanoic acid (\#15), 6-methyl-2,2'-bipyridine 1-oxide (\#27), 1,4 diaza-2,5dioxobicyclo [4.3]nonane (\#32) and benzene, (1-methyldodecyl)- for titanium tanned samples, what justifies such clustering.

This symmetry in behavior is not observed between samples within the group of the organic tanning. More differences in the order of sample clustering are shown in dendrogram. In relation to glutaraldehyde samples, untreated leather and leather treated with $\mathrm{MnCl}_{2}$ are grouped first in a second level, unlike inorganic tanned samples. In methylacrylic samples, the second level is formed by the group of leather treated with both chlorides, but then, untreated methylacrylic sample is added to the previous glutaraldehyde group, instead of being added to its respective group of treated samples as it is observed in inorganic tanned samples. The last addition in the cluster is the glutaraldehyde sample treated with $\mathrm{CoCl}_{2}$, which appears quite far away from the sample treated with $\mathrm{MnCl}_{2}$ and the sample without treatment. This clustering order can be explained by a higher influence of the chloride treatment in the organic tanned samples, especially in the case of the glutaraldehyde sample treated with $\mathrm{CoCl}_{2}$.
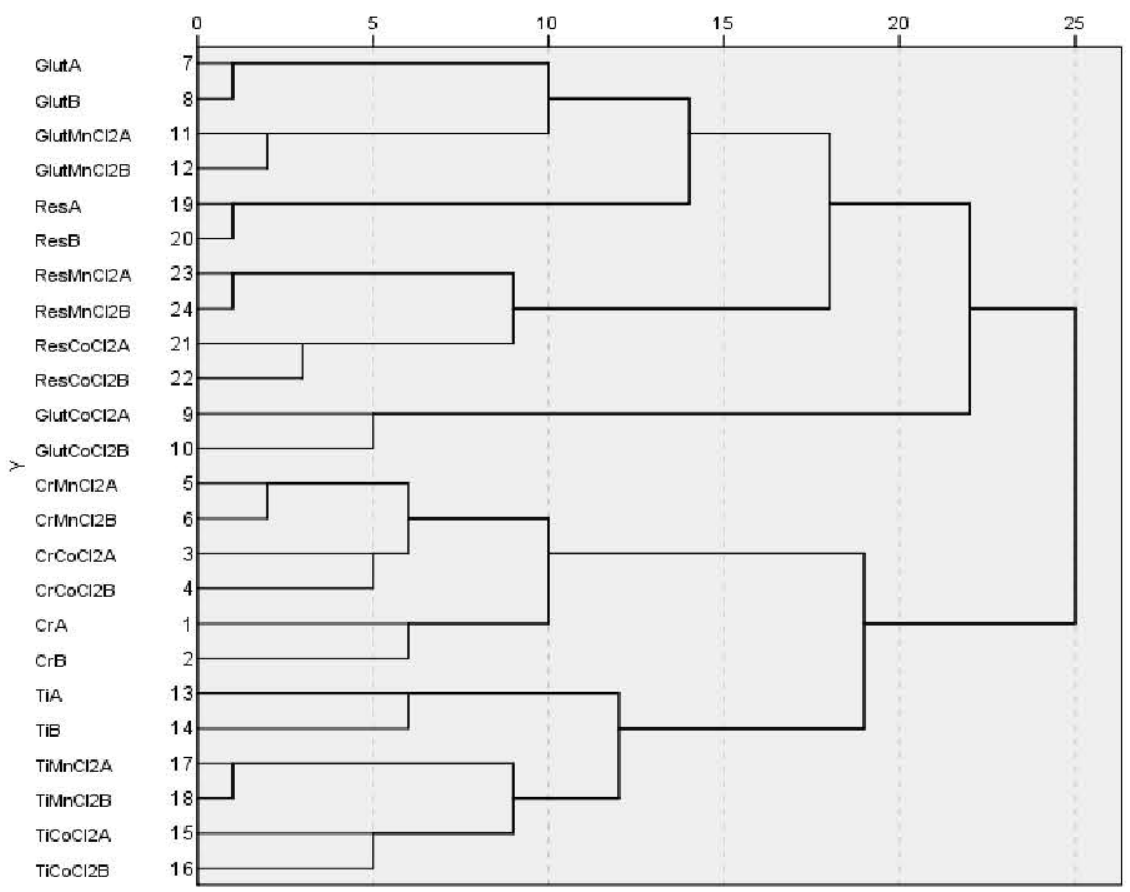

Figure 4. Dendrogram obtained from the analysis of the hierarchical clusters 
By relating the results observed in dendrogram of Figure 4 with the compounds of Table II, we have pointed out previously that glutaraldehyde sample treated with $\mathrm{CoCl}_{2}$ shows a significant increase in the amount of nonanoic acid (\#15) and a significant decrease in the amount acid 9-octadecenoic (\#43) in relation with the amount obtained in the original glutaraldehyde sample and the sample treated with $\mathrm{MnCl}_{2}$. It can also be observed that five compounds (peaks \#15, 27, 29, 31 and 39) show different behavior in methylacrylic leather treated with $\mathrm{CoCl}_{2}$ with respect to the untreated leather and the leather treated with $\mathrm{MnCl}_{2}$, which would explain the clustering order of this sample in dendrogram.

\section{Conclusions}

Pyrolysis technology does not reduce the amount of waste generated in a process but allows its disposal and valorization by converting it into a source of energy or added-value products. The study of the catalytic pyrolysis is interesting since the presence of a catalyst can improve the benefits of the pyrolysis by reducing the process temperature and/ or increasing the yield of certain interesting products.

In this paper, the catalytic effect of $\mathrm{CoCl}_{2}$ and $\mathrm{MnCl}_{2}$ on the pyrolysis of different tanned leather samples has been studied. The results indicate that these salts clearly influenced the nature of the products obtained and slightly modified the operating temperature. Thus, the thermogravimetric study shows a slight decrease in the temperature of maximum decomposition rate, ranging from $4^{\circ} \mathrm{C}$ to $8^{\circ} \mathrm{C}$. Chrome tanned leather was less affected by the catalysts' soaking treatment because chrome has already modified most of the thermal behavior of collagen.

The study of volatile products obtained after flash pyrolysis shows that the influence level of the chlorides on the products obtained depends on the tanning agent in the sample. It was found that the percentage of acid compounds detected decreased with the chloride treatment, with a particular marked decrease of 9-octadecenoic acid. On the contrary, the percentage of aromatics (important products in the chemical industry) increased in all samples after the chloride treatment, with specially marked increases for benzene (1-methyldodecyl)-. The methylacrylic tanned leather gave a significant increase in phenol yield (essential for production of many polymers and chemical products) with the chloride treatment. This behavior was not observed with other leather samples. Finally, the group formed by ketones and aldehydes (remarkable products in chemical industry) also increased in all samples, except for the chrome sample treated with $\mathrm{CoCl}_{2}$.

A multivariate statistical analysis confirmed that the inorganic tanning agents (chromium and titanium salts) produced such significant modifications to the leather structure that prevented/minimized posterior alterations, being less sensitive to the chloride treatment than the organic agents (glutaraldehyde and methylacrylic polymer).

\section{Acknowledgements}

Co-financial support for this investigation has been provided by IMPIVA, Generalitat Valenciana, and FEDER for research within the field of pyrolysis flash of leather waste.

\section{References}

1. http://ec.europa.eu/environment/waste/

2. Tahiri, S., De la Guardia, M.; Treatment and valorization of leather industry solid waste: a review. JALCA 104, 52-67, 2009.

3. Tahiri, S., Bouhria, M., Albizane, A., Messaoudi, A., Azzi, M., Alami Younssi, S., Mabrour, J.; Extraction of proteins from chrome shavings with sodium hydroxide and reuse of chromium in the tanning process. JALCA 99, 16-25, 2004.

4. Muralidhara, HS., Maggin, B., Phipps Jr., H.; Conversion of tannery waste to useful products. Resour. Conserv., 8, 43-59, 1982.

5. Caballero, J.A., Font, R., Esperanza, M.M.; Kinetics of the thermal decomposition of tannery wastes. J. Anal. Appl. Pyrol., 47, 165-181, 1998.

6. Yilmaz, O., Kantarli, I.C., Yuksel, M., Saclam, M., Yanik, J.; Conversion of leather wastes to useful products. Resour. Conserv. Recy., 49, 436-448, 2007.

7. Oliveira, LCA., Guerreiro, MC., Gonçalves, M., Oliveira, DQL., Costa, LCM.; Preparation of activated carbon from leather waste: a new material containing small particle of chromium oxide. Mater. Lett., 62, 3710-3712, 2008.

8. Marcilla, A., García, A.N., León, M., Martínez, P., Bañón, E.; Analytical pyrolysis as a method to characterize tannery wastes. Ind. Eng. Chem. Res., 50, 8994-9002, 2011.

9. Marcilla, A., García, A.N., León, M., Martínez, P. and Bañón, E.; Study of the influence of $\mathrm{NaOH}$ treatment on the pyrolysis of different leather tanned using thermogravimetric analysis and $\mathrm{Py} /$ GC-MS system. J. Anal. Appl. Pyrol., 92, 194-201, 2011.

10. Marcilla, A., León, M., García, A.N., Bañón, E., Martínez, P.; Upgrading of Tannery Wastes under Fast and Slow Pyrolysis Conditions. Ind. Eng. Chem. Res., 51, 3246-3255, 2012.

11. Marcilla, A., García, A.N., León, M., Bañón, E., Martínez, P.; Characterization of Commercially Available Leathers Using Thermogravimetric Analysis and Py/GC-MS Systme. JALCA, 107, 220-230, 2012.

12. Bañón, E., Marcilla, A., García, A.N., Martínez, P, León, M.; Kinetic model of the thermal pyrolysis of chrome tanned leather treated with $\mathrm{NaOH}$ under different conditions using thermogravimetric analysis. Waste Manage., 48, 285-299, 2016.

13. Simioni, T., Matos, E., Marcondes Bacca, V., Perondi, D., Godinho, M., Dettmer, A.; Pyrolysis of chrome leather waste shavings in fluidized bed. JALCA 109, 342-352, 2014.

14. Sethuraman, C., Srinivas, K., Sekaran, G.; Double pyrolysis of chrome tanned leather solid waste for safe disposal and products recovery. IJSER, 4, 61-67, 2013.

15. Font, R., Marcilla, A., Verdú, E., Devesa, J.; Catalytic pyrolysis of almond shells: influence of temperature and $\mathrm{CoCl} 2$ to almond shells ratio. Can. J. Chem. Eng., 68, 312-318, 1990. 
16. Conesa, J. A., Marcilla A. and Caballero, J. A.; Evolution of gases from the pyrolysis of modified almond shells: effect of impregnation with CoCl2. J. Anal. Appl. Pyrol., Vol. 43, no. 1, 59-69, 1997.

17. Khelfa, A., Finqueneisel, G., Auber, M. and Weber, J. V.; Influence of some minerals on the cellulose thermal degradation mechanisms - Thermogravimetic and pyrolysis-mass spectrometry studies. J. Therm. Anal. Calorim., 92, 3, 795-799, 2008.

18. Rutkowski, P.; Catalytic effects of copper (II) chloride and aluminium chloride on the pyrolitic behavior of cellulose. J. Anal. Appl. Pyrol., 98, 86-97, 2012.

19. Zou, X., Yao, J., Yang, X., Song, W. and Lin, W.; Catalytic effects of metal chlorides on the pyrolysis of lignite. Energ. Fuel, 21, 619-624, 2007.

20. Wan, Y., Chen, P., Zhang, B., Yang, C., Liu, Y., Lin, X., Ruan, R.; Microwave-assisted pyrolysis of biomass: Catalysts to improve product selectivity. J. Anal. Appl. Pyrol., 86, 161-167, 2009.

21. Özbay, G., Özçifçi, A., Karagöz, S.; Catalytic Pyrolysis of Waste Melamine Coated Chipboard. Environ. Prog. Sustain. Energ., 32, 156-161, 2013.

22. Eibner, S., Broust, F., Blin, J., Julbe, A.; Catalytic effect of metal nitrate salts during pyrolysis of impregnated biomass. J. Anal. Appl. Pyrol., 113, 143-152, 2015.

23. Longjun, L., Xiaoqian, M., Qing, X., Zhifeng, H.; Influence of microwave power, metal oxides and metal salts on the pyrolysis of algae. Bioresource Technol., 142, 469-474, 2013.
24. Müller, J. and Dongmann, G.; Formation of aromatics during pyrolysis of PVC in the presence of metal chlorides. J. Anal. Appl. Pyrol., 45, 59-74, 1998.

25. Chiu, S.J. and Cheng, W. H.; Thermal degradation and catalytic cracking of poly(ethylene terephthalate). Polym. Degrad. Stabil., 63, 3, 407-412, 1999.

26. Sablier, M., Sala, M., Kitahara, Y., Takahasi, S., Fujii, T.; Influence of copper chloride for the formation of aromatic compound during polyethylene pyrolysis. J. Anal. Appl. Pyrol., 89, 178-182, 2010.

27. Chiu, S-J., Chen, S-H, Tsai, C-T.; Effect of metal chlorides on thermal degradation of (waste) polycarbonate. Waste Manage., 26, 252-259, 2006

28. Terakado, O., Yanase, H., Hirasawa, M.; Pyrolysis treatment of waste polyurethane foam in the presence of metallic compounds. J. Anal. Appl. Pyrol., 108, 130-135, 2014

29. Chalov, K.V., Lugovoy, Yu.V., Doluda, V.Yu., Sidorov, A.I., Sulman, M.G., Kosivtsov, Yu.Yu., Tkachenko, O.P., Sulman, E.M.; Influence of metals chlorides on oil-slime thermocatalytic processing. Chem. Eng. J., 238, 219-226, 2014.

30. Bañón, E. Dissertation PhD Thesis: Study of the pyrolysis of leather. Characterization and recycling. University of Alicante, 2015.

31. Pocket book for leather technologist. Fourth edition. BASF. 2007. 